\title{
Multiple Disseminated Pink Papules in Patient with Myelodysplastic Syndrome: A Quiz
}

Edyta LELONEK ${ }^{1}$, Martyna BIAŁA ${ }^{2}$ and Jacek C. SZEPIETOWSKI ${ }^{1}$

${ }^{1}$ Department and Clinic of Dermatology, Venereology and Allergology, Wroclaw Medical University, 50-368 Wrocław, Chałubińskiego 1, Poland and ${ }^{2}$ Department of Infectious Diseases, Liver Diseases and Acquired Immune Deficiencies, Wroclaw Medical University, Wrocław, Poland. Email: elelonek@gmail.com

A 57-year-old Caucasian woman with a 1-year history of swollen and painful wrists and metacarpophalangeal joints of the hands presented with generalized papular eruption and "malar-rash" on the cheeks.

The skin eruption began as erythematous lesions distributed on the cheeks with the exception of the nasolabial folds. The rash was preceded by pain in the knee and wrist joints, with a restriction of mobility. The symmetrically distributed, symptomless, pink, small, singular papules progressed to involve the head, upper and lower limbs. On the trunk the lesions coalesced into brownish plaques (Fig. 1). The patient also presented with skin erythema on the head and confluent white patches and erosions on the hard palate. The patient additionally experienced iridocyclitis during the course of the disease. A complete blood cell count with differential showed macrocytic anaemia with high rate of reticulocytosis, thrombocytopaenia and IgM monoclonal gammopathy. The haematological abnormalities progressed slowly over one year, and the subsequent biopsy of the bone marrow confirmed the diagnosis of myelodysplastic syndrome (MDS).

Patient's medical history was positive for a non-toxic goitre, ischaemic heart disease and myocardial infarction.

A punch biopsy was taken with subsequent histological examination. The histopathological picture revealed granulomatous infiltrate composed mainly of lymphocytes with mixed epithelial cells and single multinucleated giant cells, degeneration of collagen and the presence of macrophages CD68 ${ }^{+}$(Fig. 2).

What is your diagnosis? See next page for answer.
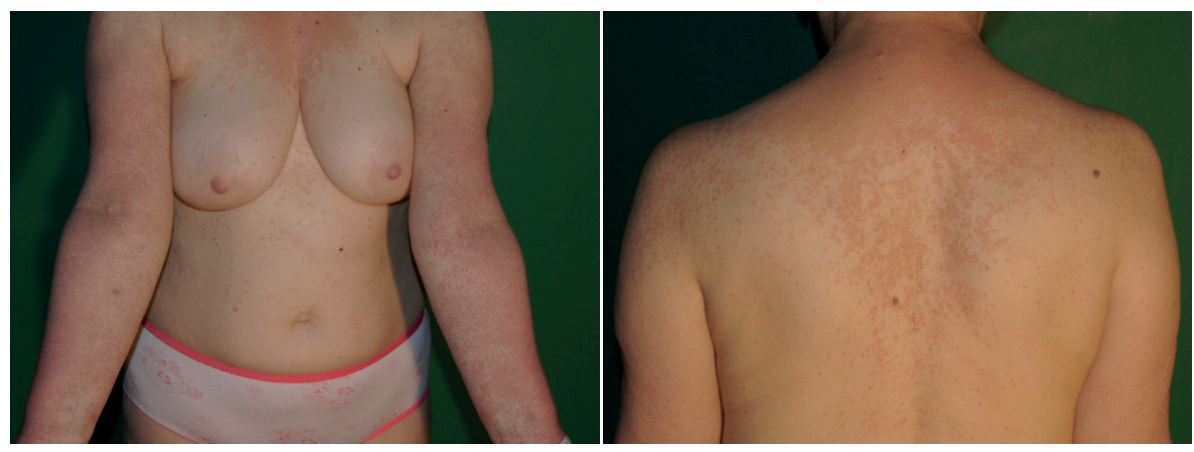

Fig. 1. Diffuse and symmetrically distributed erythematous papules and plaques on $(A, B)$ the trunk and upper limbs, (C) the lower extremities.

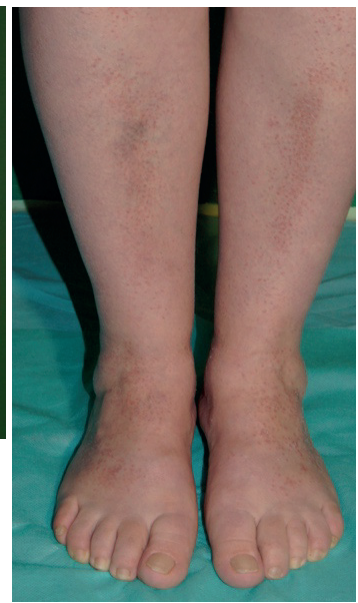

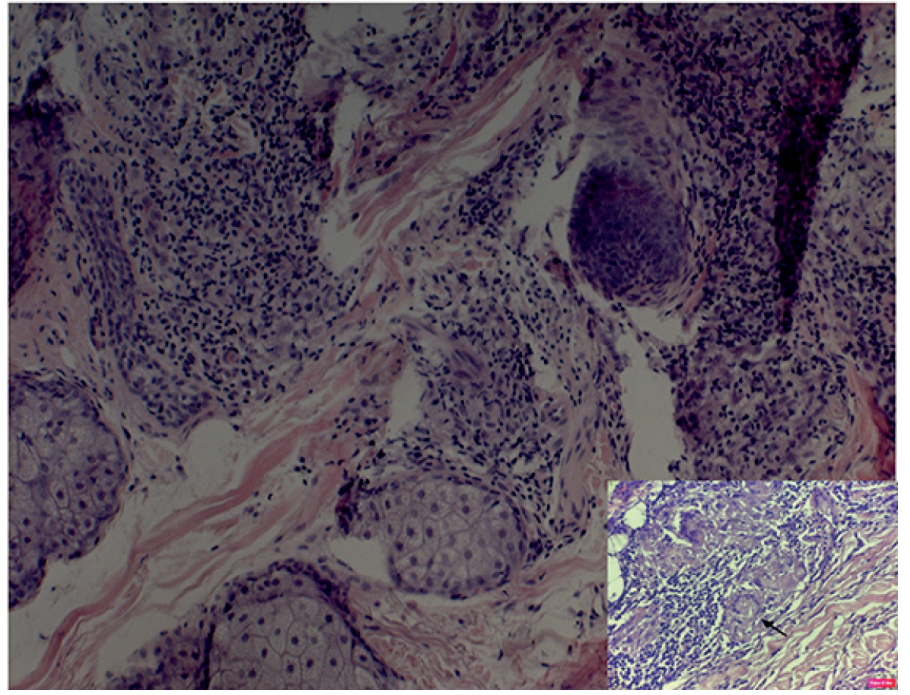

Fig. 2. Granulomatous infiltrate with mixed epithelial cells and single multinucleated giant cells (black arrow), degeneration of collagen (haematoxylin and eosin stain $\times 40$ magnification). 


\section{ANSWERS TO QUIZ}

\section{Multiple Disseminated Pink Papules in Patient with Myelodysplastic Syndrome: A Commentary}

Acta Derm Venereol 2021; 101: adv00620.

\section{Diagnosis: Generalized interstitial granulomatous dermatitis as a first sign of myelodysplastic syndrome}

Generalized interstitial granulomatous dermatitis (IGD) is a rarely reported entity in medical literature (only a few cases have been published), which was first recognized by Ackerman et al. in 1993 (1). IGD is described as one of the several granulomatous inflammatory skin reactions with similar clinical and histological features, such as palisaded neutrophilic granulomatous dermatitis and interstitial granulomatous drug reaction (2). The exact pathogenesis of IGD is unknown, but it is frequently associated with autoimmune diseases such as rheumatoid arthritis, Sjögren's syndrome and systemic lupus erythematosus. IGD is also described in association with drug reactions, solid-organ cancers, such as breast cancer, hypopharyngeal squamous cell carcinoma and lung cancer, and haematological malignancies, such as myeloproliferative disorders and MDS (3-6).

Clinically, IGD is characterized by variable manifestations, mainly as asymptomatic, symmetrically distributed papules and plaques, changing in colour from skin-coloured to erythematous and frequently located in the lateral upper trunk, axillae and proximal upper limbs. The characteristic morphological feature of IGD is a violaceous subcutaneous linear cord or band known as the "rope sign". Other findings include diffuse macular erythema, annular plaques, polycyclic indurated plaques, annular scaly plaques, subcutaneous nodules, large atrophic hyperpigmented plaques and periungal and mucosal erythema (2-4).

Histopathological findings of IGD are characterized by necrotizing granulomatous inflammation with interstitial pattern. The infiltration is scattered around degenerated collagen bundles and blood vessels of the dermis and consists of $\mathrm{CD}^{+} 8^{+}$epithelioid histiocytes. The histiocytic infiltrate may be rarely accompanied by eosinophils and neutrophils (2-7).

The clinicopathological features of IGD and granuloma annulare (GA) have many similarities. Therefore, the differential diagnosis can be challenging. It should be emphasized that, when considering the next steps in the diagnosis, it is important to rule out potentially associated diseases. The spectrum of described correlations with metabolic, endocrine, and neoplastic diseases is wide and need to be emphasized. Moreover, the IGD might appear before or after the diagnosis of an underlying malignancy.
The effective therapeutic options include topical or systemic glucocorticosteroids, dapsone, colchicine, methotrexate, 5-azacytidine and tumour necrosis factor alpha (TNF-alpha) blockers with spontaneous remission rate from 3 months to 3 years among two-thirds of patients $(8-10)$.

In the described case treatment with systemic glucocorticosteroids (prednisone $40 \mathrm{mg}$ daily) was initiated and resulted in remission of skin lesions within 3 weeks of therapy.

Granulomatous dermatitis could be the first sign of haematological disorders, including MDS, but the knowledge about this uncommon association is rather poor. This case illustrates an important relationship of IGD preceding MDS, which dermatologists should take into consideration during differential diagnosis, because the underlying MDS could progress to leukaemia.

\section{REFERENCES}

1. Ackerman AB. Histologic diagnosis of inflammatory skin diseases: interstitial granulomatous dermatitis with arthritis. In: Ackerman AB, Guo Y, Vitale $P$, editors. Clues to diagnosis in dermatopathology. 1st edn. Chicago: ASCP Press, 1993: p. 309-312.

2. Rosenbach M, English JC, 3rd. Reactive granulomatous dermatitis: a review of palisaded neutrophilic and granulomatous dermatitis, interstitial granulomatous dermatitis, interstitial granulomatous drug reaction, and a proposed reclassification. Dermatologic Clinics 2015; 33: 373-387.

3. Peroni A, Colato C, Schena D, Gisondi P, Girolomoni G. Interstitial granulomatous dermatitis: a distinct entity with characteristic histological and clinical pattern. $\mathrm{Br}$ J Dermatol 2012; 166: 775-783.

4. Veronez IS, Dantas FL, Valente NY, Kakizaki P, Yasuda TH, Cunha Tdo A. Interstitial granulomatous dermatitis: rare cutaneous manifestation of rheumatoid arthritis. An Bras Dermatol 2015; 90: 391-393.

5. Thompson L, Abner S, Malone J, Callen JP. Interstitial granulomatous dermatitis as the initial manifestation of myeloma. JAMA Dermatol 2015; 151: 1141-1142.

6. Magro CM, Crowson AN, Schapiro BL. The interstitial granulomatous drug reaction: a distinctive clinical and pathological entity. J Cutan Pathol 1998; 25: 72-78.

7. Coutinho I, Pereira N, Gouveia M, Cardoso JC, Tellechea O. Interstitial granulomatous dermatitis: a clinicopathological study. Am J Dermatopathol 2015; 37: 614-619.

8. Balin SJ, Wetter DA, Kurtin PJ et al. Myelodysplastic syndrome presenting as generalized granulomatous dermatitis. Arch Dermatol 2011; 147: 331-335.

9. Blaise S, Salameire D, Carpentier PH. Interstitial granulomatous dermatitis: a misdiagnosed cutaneous form of systemic lupus erythematosus? Clin Exp Dermatol 2008; 33: 712-714.

10. Patsinakidis $\mathbf{N}$. et al. Interstitial granulomatous dermatitis associated with myelodysplastic syndrome - complete clearance under therapy with 5-azacytidine. Acta Derm Venereol 2014; 94: 725-726. 